\title{
A RELAÇÃO SER HUMANO E NATUREZA A PARTIR DA VISÃO DE ALGUNS PENSADORES HISTÓRICOS ${ }^{1}$
}

\author{
Vinicius Perez Dictoro \\ Rodolfo Antônio de Figueiredo ${ }^{3}$ \\ Murilo Otávio Cassimiro 4 \\ Juliano Costa Gonçalves ${ }^{5}$
}

Resumo: A importância do estudo da filosofia e da Educação Ambiental, assim como a relação entre ser humano e natureza nos remete a conhecer um pouco sobre a história da vida sobre a Terra. O presente estudo visa possibilitar entender melhor, discutir e refletir sobre algumas concepções da relação ser humano e natureza, conforme o desenvolvimento da época filosófica e da ciência, por meio de alguns textos sobre as obras de alguns filósofos da cultura ocidental. $\mathrm{O}$ artigo foi elaborado a partir de revisões bibliográficas e estudos teóricos sobre os seguintes filósofos: pré-socráticos; Bacon; Descartes; Kant; Espinosa. Busca-se valorizar novas ideias, modelos e direções que consideram os distintos pensadores, suas reflexões e o contexto histórico de cada um.

Palavras-chave: Ser Humano e Natureza; Compreensão Ambiental; Educação Ambiental.

${ }^{1} \mathrm{O}$ presente trabalho foi realizado com apoio da Coordenação de Aperfeiçoamento de Pessoal de Nível Superior - Brasil (CAPES) - Código de Financiamento 001.

2Universidade Federal de São Carlos. E-mail: vinicius.dictoro@gmail.com. Link para o Lattes: http://lattes.cnpq.br/9469471717661914.

3Universidade Federal de São Carlos. E-mail: rodolfo@ufscar.br. Link para o Lattes: http://lattes.cnpq.br/0854609216769461.

${ }^{4}$ Universidade Federal de São Carlos. E-mail: murilo_295@hotmail.com. Link para o Lattes: http://lattes.cnpq.br/3427583614605440.

5 Universidade Federal de São Carlos. E-mail: juliano@ufscar.br. Link para o Lattes: http://lattes.cnpq.br/1803562162325019. 


\section{Introdução}

Este artigo foi escrito a partir da leitura, reflexão e discussão dos textos de autoras e autores presentes no livro Pensar o ambiente: bases filosóficas para Educação Ambiental (CARVALHO et al., 2006), além de outras referências bibliográficas e artigos científicos sobre a temática. Nessa proposta, os autores que escrevem este ensaio, procuram mostrar algumas visões sobre as relações dos seres humanos com a natureza por meio dos seguintes pensadores: pré-socráticos, Bacon, Descartes, Kant e Espinosa.

Vale destaque inicial, que nas obras citadas acima os autores utilizam e fazem referência à relação "Homem e natureza". Essa referência trata-se de uma expressão da ciência de séculos anteriores, marcadamente eurocêntrica e masculina. Contudo, as críticas filosóficas, teorias feministas e os estudos sobre gênero já descortinaram os componentes dessa expressão. Assim o presente artigo irá substituir esses termos por palavras mais adequadas com a realidade atual global, utilizando a expressão "ser humano e natureza".

Deve-se em um primeiro momento situar sobre o que se trata a filosofia. Segundo Chauí (2002), uma nova forma de pensar, na Grécia antiga, surgiu a palavra filosofia, vinda de amizade e sabedoria, tratando-se da amizade pela sabedoria ou amor ao saber. Existem duas interpretações que se tornaram frequentes no decorrer da história, remetendo-se a filosofia como o conjunto sistemático e racional de conhecimentos sobre o mundo e os seres humanos ou, também, pode significar a sabedoria entendida como disposição humana para uma vida virtuosa e feliz (CHAUÍ, 2002).

A importância do estudo da filosofia e da Educação Ambiental, assim como a relação humana com a natureza nos remete a conhecer um pouco sobre a história da vida sobre a Terra, que conforme Carson (1969), tem sido uma história de interação entre as coisas vivas e o seu meio ambiente. A atenção dirigida pelos seres humanos para a natureza não data de um período específico, é preferível dizer que esse diálogo, ser humano e natureza, tenha começado com a própria humanidade e nunca será interrompido (LENOBLE, 2002).

Ao longo dos anos e dos espaços sociais existem diversos sentidos e definições para caracterizar a natureza, entretanto na maioria dos casos ela não pode ser compreendida de forma separada do ser humano, pois ao se falar em natureza necessariamente está sendo relacionado o ser humano, ainda que historicamente houve momentos de uma maior ou menor aproximação entre essa relação (DUARTE, 2003).

Segundo Lenoble (2002), toda a ideia de natureza implica em uma complexa aliança de aspectos morais, científicos, religiosos, afetivos e artísticos, que dominam uma época e inspiram a forma de perceber o mundo.

Entretanto, na expressão filosófica científica separa-se ser humano e natureza, ressaltando o aspecto utilitarista da natureza para o proveito humano. Nessa visão, ressaltando o modo de produção capitalista, a natureza e os 
seres humanos são considerados objetos para obtenção de lucro, sendo uma das causas que levou a humanidade a viver na atual crise socioambiental (FIGUEIREDO; SILVA, 2018).

No final do século XX, mais precisamente na década de 1980, surge a cosmovisão contemporânea da natureza. Conforme explica Pelizzoli (1999, p. 65) nessa compreensão o universo passa a ser visto como uma rede de relações vivas, que incluem o ser humano como próprio observador, assim como ator e não apenas como mero espectador passivo e neutro.

Dessa forma, o presente estudo visa a possibilidade de entender melhor, discutir e refletir sobre algumas concepções da relação ser humano e natureza, conforme o desenvolvimento da época filosófica e da ciência, por meio de alguns textos sobre as obras de importantes pensadores e filósofos da cultura ocidental.

\section{Ser humano e natureza sob a visão dos pensadores pré-socráticos}

Os filósofos pré-socráticos, primeiros que se tem notícia na Grécia antiga, eram conhecidos por filósofos da natureza, por se importarem com o estudo da natureza e de seus processos. Mesmo que tinham várias divergências sobre os elementos e princípios que regem o universo, esses filósofos compartilhavam a visão de que o todo integra a natureza, ou seja, o ser humano, a sociedade, o mundo exterior e até os deuses são integrados à natureza (SOFFIATI, 2000). Destaca-se que são caracterizados pré-socráticos não porque todos teriam nascido e vivido antes de Sócrates, mas pelos temas que abordam em suas reflexões (CHAUÍ, 2002).

De início, parte-se para a compreensão do mundo por alguns pensadores pré-socráticos que combatiam a visão objetiva, tanto sobre a natureza, como para o ser humano. Segundo a autora Unger (2006), a visão de mundo na qual tanto a natureza como os seres humanos foram reduzidos à condição de objetos, na qual os valores são baseados apenas no capital e no lucro, foi repensada pelo pensamento pré-socrático, visando novos valores do lugar do ser humano no universo, proporcionando uma chance de reflexão.

Nota-se a filosofia como uma cosmologia, voltada para a explicação da natureza por meio do princípio primordial gerador de todas as coisas, assim como o processo de formação e de ordem do mundo (CHAUí, 2002).

O esforço para dialogar com esse modo de pensamento é uma provocação e um convite para se deparar com os hábitos e compreensões, podendo a partir disso, abrir novos caminhos para pensamentos mais livres e mais abertos na relação do ser humano com o Universo e seu lugar neste sistema (UNGER, 2006). Dessa visão, entende-se que a relação ser humano e natureza deve ser valorizada e principalmente respeitada, não pensada apenas como objetos de uso e apropriação. 


\section{Ser humano e natureza sob a visão de Francis Bacon e René Descartes}

Parte-se para outra época, dos pensadores do século XVI, na qual se começa a praticar o conhecimento de forma autônoma, dispensando a interferência de forças transcendentais (mitos, religião, crenças) (SEVERINO, 2006). Nesse contexto, que se estuda o pensamento filosófico de Francis Bacon e René Descartes, com uma visão racionalista e mecânica do mundo e da compreensão da natureza.

Surge a ideia de ciência, sendo um novo sistema do saber, baseada e referenciada por Bacon, uma nova e revolucionária instância da cultura ocidental, que vai mudar completa e definitivamente a visão da relação do ser humano com o mundo. Um novo sistema de saber, distinto tanto do sistema teológico como do sistema metafísico, que se propõe como capaz de esclarecer a totalidade dos fenômenos do universo apenas com os recursos da razão natural (SEVERINO, 2006). Dessa forma, Francis Bacon via a ciência como uma forma de devolver ao ser humano o domínio sobre a criação e assim sobre a natureza (THOMAS, 1996).

Essa ciência, surgida e baseada em Francis Bacon e René Descartes passou a enxergar a natureza como um mecanismo a ser controlado, uma máquina a ser investigada, dominada e utilizada. Houve então a separação da cultura humana com a natureza (HERCULANO, 1992). Por essa visão mecanicista, a natureza perde a finalidade que os antigos filósofos julgavam encontrar nela, tornando-se simplesmente uma máquina (LENOBLE, 2002).

Bacon e Descartes ousam tornar-se "donos e senhores da natureza", sendo que proclamam que obtêm de Deus este domínio e essa posse. Tendo recebido de Deus a missão de utilizar a natureza, o ser humano começa a comportar-se como um engenheiro que já não necessita direcionar qualquer valor à natureza (LENOBLE, 2002). Nesse contexto reflete-se na relação do ser humano com a natureza, convertendo-a em uma relação de domínio e de proveito para a vida humana. Segundo Acosta (2016, p. 55), a dominação foi possível quando esses pensadores passaram a não considerar os seres humanos como parte da natureza, "desconhecendo que os seres humanos também somos Natureza". Pode-se considerar Bacon como o precursor do desencantamento do mundo, surgindo uma visão racionalista e de apropriação sobre a natureza.

Essa concepção pode ter ajudado a desencadear um longo processo histórico de domínio e manejo do mundo, alterando as próprias condições de convivência do ser humano com a natureza e com a sobrevivência do planeta (SEVERINO, 2006). Segundo Francis Bacon "o homem pode ser visto como o centro do mundo", ressaltando ainda que se o ser humano fosse retirado do mundo, todo o resto pareceria sem propósito (THOMAS, 1996).

Reforçando e intensificando essas concepções, René Descartes, filósofo francês do século XVII, é considerado a base de todo o pensamento moderno. Soffiati (2000) destaca que René Descartes é considerado como o maior 
exponente da separação entre ser humano e o mundo, pois deposita na razão humana a possibilidade de dar significado e interpretação ao mundo, sendo a compreensão do mundo baseada no pensar e questionar humano, desprovido dos mitos e de significações pré-concebidas.

Suas ideias influenciaram muito a atual relação com a natureza, a objetividade cartesiana fez com que "perdêssemos" a possibilidade de pensar historicamente e colocou o ser humano na posição de dono e senhor da natureza (GRÜN, 2006).

A filosofia de Descartes influenciou a informação do sujeito liberal, pois aqui ele é visto como liberto de quaisquer raízes. Existia independentemente de tudo que estava fora dele, incluindo os ecossistemas e o ambiente natural (GRÜN, 2006). Dessa forma, a harmonia entre o mundo e o ser humano é rompida, o ser humano torna-se sujeito, e o mundo seu objeto, onde a natureza é utilizada da maneira que o ser humano quer, exemplificada pela frase "senhores e possuidores da natureza". Segundo Thomas (1996) o propósito explícito de Descartes adequava-se à sua intenção que as todas as outras espécies eram inertes e desprovidas de qualquer dimensão espiritual, devido a isso, instaura-se um corte entre ser humano e natureza, limpando o terreno para o exercício da dominação humana.

Vê-se aqui um antropocentrismo extremista, tornando o ser humano como senhor e possuidor da natureza. Pela visão dos autores que escrevem esse estudo, essa compreensão, baseada na objetividade cartesiana, reflete aspectos da ação da humanidade que temos presenciado durante esses séculos e que ainda é vista atualmente. A noção da natureza como fonte inesgotável para uso dos seres humanos vem dessa base de pensamento, onde não acontece qualquer tipo de intervenção ética sobre a existência da natureza por si própria.

Essa visão, subsidiada pelo pensamento de Descartes, trata-se de uma formulação cartesiana na qual a ciência é vista no sentido de domínio da natureza, ou seja, as razões de Descartes ligam-se à dominação, pois o fim é o da utilização da natureza em proveito da humanidade, configurando-se em um pensamento antropocêntrico (MARICONDA, 2006).

\section{Ser humano e natureza sob a visão de Immanuel Kant e Espinosa}

Passando pelas ideias e alguns pensamentos do filósofo Immanuel Kant, nota-se ainda de forma tímida, uma amenização da relação do ser humano com a natureza, do modo como é vista por Descartes.

Mesmo que a objetificação da natureza é presente nesses pensamentos de Kant, parece haver uma retomada à natureza, o ser humano sente-se em casa na Terra, e pelo desenvolvimento do sentido de gosto, aprende a amar a natureza e a vida, e assim cuidando dela (ROHDEN, 2006). 
Observa-se na reflexão feita por Rohden (2006, p. 115) sobre essa relação ser humano e natureza a partir do pensamento de Kant:

"O prazer que o ser humano sente pelos outros e pela natureza é sempre um prazer na vida. Por esse prazer, principalmente pelo prazer estético, o ser humano sente-se bem no mundo; e já por isso ele passará a cuidar da natureza".

Mesmo que pautada no prazer e em uma razão atribuída por um fim próprio para o ser humano, a relação com a natureza possui um certo valor e um desejo de cuidar, pois o ser humano é visto também como um ser da natureza, diferentemente da visão totalmente separada que Descartes elucida.

Nas reflexões de Kant buscou-se o reencontro do ser humano com a natureza, por meio da passagem de um pensamento fragmentário a um pensamento organizado pela ideia do todo (JORDÃO, 1992).

Essa relação fragmentada entre ser humano e natureza deve ser superada, sendo baseada na crença das sociedades voltarem a entender tanto o ser humano como a natureza como entes sagrados, e ainda incumbindo à ação humana uma importância essencial na transformação do mundo (FIGUEIREDO; SILVA, 2018).

Assim, tem-se nos pensamentos de Espinosa uma outra forma de pensar sobre a relação ser humano e natureza, contribuindo para outras visões e compreensões do mundo. Mesmo sendo um expoente do racionalismo europeu, assim como Bacon, Descartes e Kant, Espinoza deles se afastava por entender que tudo que é contrário à natureza seria contrário à razão (ACOSTA, 2016, p. 124).

No contexto vivido por Espinosa, o controle sobre a natureza era uma aspiração visando melhorar a qualidade de vida, e a ciência vinha com a notável promessa de possibilitar o domínio da natureza e a correspondente superação dos limites produtivos por ela impostos ao ser humano. Entretanto, Espinosa fez importantes críticas a esse modo de pensar e tratar a natureza submetendo-a à vontade dos seres humanos (SAWAIA, 2006).

Nos pensamentos e reflexões de Espinosa, a natureza é vista e explicada por vontade própria e não feita para o uso do ser humano. Volta-se a ideia de pensar e integrar o ser humano ao cosmo, possuindo um leve caráter de combate ao antropocentrismo.

Surge nas reflexões de Espinosa a ética da totalidade, na qual ocorre uma exaltação da natureza. Conforme Sawaia (2006) a ética da totalidade considera-se que, ao maltratar o mundo, você está maltratando a si mesmo, propondo, em lugar da conquista da natureza pelo ser humano, a libertação de ambos. Os valores éticos devem ser pensados globalmente, baseando-se em 
toda a natureza. Desses excertos (obras de Espinosa) que começam a surgir a fundamentação da ética ambiental.

Ainda segundo o autor, Espinosa defende a elaboração de um paradigma ecológico, por meio da conexão de todas as coisas, pessoas, objetos, animais e o planeta em uma rede, conservando e respeitando suas relações e inter-relações (SAWAIA, 2006).

\section{Uma breve discussão sobre os tópicos}

Perpassando por apenas alguns trechos que esses pensadores e filósofos discorreram sobre a relação ser humano e natureza, nota-se diferentes formas de compreender e enxergar o papel dos seres humanos no mundo. Dessa forma, os autores desse artigo irão expor suas opiniões sobre alguns aspectos dessa relação que foi sendo levantada e discutida brevemente nos parágrafos acima.

Hoje, vive-se em um período que pode ser chamado de Antropoceno, onde a intervenção humana tem causado intensas transformações na natureza. Conforme Carson (1969), a rapidez da mudança e a velocidade com que novas situações se criam acompanham o ritmo impetuoso e insensato do ser humano, ao invés de acompanhar o passo deliberado da natureza. As mudanças nas formas de pensar e agir do ser humano na natureza foram sendo transformadas durantes os anos. A crença do total controle sobre a natureza pode ter sido baseada em Francis Bacon, intensificada por René Descartes, discutida por Immanuel Kant, e de certa forma combatida por Espinosa.

A crítica não está nas formas de pensar e compreender o mundo desses pensadores (Bacon e Descartes principalmente), que viviam em contexto completamente diferente da época de hoje, e isso pode ter se refletido em suas maneiras de pensar e enxergar o mundo. Porém, muito da atual relação dos seres humanos com a natureza vem da base do pensamento cartesiano, exaltado por Descartes. As transformações e a realidade que se vivencia na natureza vem do fato de se pensá-la separada do ser humano, e em benefício próprio, resultando em desastres e impactos socioambientais que ampliam as vulnerabilidades e desigualdades em diversas questões ambientais e socioculturais.

Baseados em uma visão antropocêntrica, considera-se a natureza como um objeto e enxerga-se o ser humano como superior e não integrado a ela. Deve-se então resgatar valores, compreensões e pensamentos mais ligados a pensadores como Espinosa, de forma a reconhecer a existência da natureza por si só, e fazer parte da mesma, integrar, se relacionar, conviver e aprender.

A natureza não deve ser definida como um sistema fechado e também não deve ser separada do destino dos seres humanos, pois ela é uma imensa 
semiologia, ou seja, uma área do conhecimento dedicada a compreender os distintos ritos e costumes desenvolvidos pela sociedade (LENOBLE, 2002).

Os processos históricos de afastamento dos seres humanos perante a natureza resultaram no atual paradigma antropocêntrico utilitarista. Uma das maneiras de combater essa perspectiva é enfatizada por meio da Educação Ambiental e sua função moral de socialização humana ampliada à natureza, de forma a enxergar o ser humano como uma continuidade da natureza. Busca-se a reaproximação do humano perante a natureza, por meio da correção do rumo civilizatório, baseado na ampliação da esfera ética e ambiental e da promoção de uma mudança cultural (LAYRARGUES, 2006).

A Educação Ambiental abre espaço para repensar práticas sociais e transmitir conhecimentos essenciais para a compreensão do meio ambiente, da interdependência dos problemas ambientais e responsabilidades de cada indivíduo na luta por um ambiente cada vez melhor (JACOBI, 2003). A percepção sobre essas novas formas de interações pode partir de uma visão integradora entre seres humanos e natureza, os anseios das sociedades, e ainda na compreensão coletiva e individual dos sujeitos sobre o meio em que estão inseridos, integrando a natureza (DE PAULA, 2014).

Outro ponto, é que essa relação entre seres humanos e natureza, também podem ocasionar conflitos, tensões e problemas socioambientais. Em geral, este tipo de relação conflituosa está pautado no distanciamento das relações humanas com a natureza e o ambiente (SAUVÉ, 2005) e diretamente relacionada com a forma de apropriação dos recursos ambientais, como visto em alguns filósofos estudados. Neste sentido, "apropriação da natureza implica numa manipulação da mesma, subordinada aos fins propostos por seu dominador, que, em primeira instância, é o ser humano" (ALMEIDA, 1988, p.13). É na natureza que se encontram os elementos necessários para a vida como um todo, sendo, portanto, a fonte de subsistência seguidamente requisitada (FELIPPE, 2010).

Uma nova maneira de ser no mundo pode ser marcada pela leitura que se faz do mesmo, dessa forma a compreensão da relação ser humano e natureza precisa ser expandida. A busca pela construção de novas perspectivas, superando as atuais formas da relação cartesiana ser humano e natureza, devem propiciar uma construção conjunta e reflexiva sobre a interação dos seres humanos com o meio, com as plantas e animais, além de uma autorreflexão sobre si próprio e sua forma de se relacionar no mundo e com o mundo. Esses aspectos são discutidos e propostos em várias vertentes da Educação Ambiental.

Segundo Sauvé (2005, p. 317) "a Educação Ambiental leva-nos também a explorar os estreitos vínculos existentes entre identidade, cultura e natureza, e a tomar consciência de que, por meio da natureza, reencontramos parte de nossa própria identidade humana". 


\section{Conclusões}

De modo geral, nota-se que essas mudanças no ambiente e na natureza, causadas pelos seres humanos, advém principalmente da visão cartesiana de pensar e controlar o mundo, passando pelas ideias e visões de mundo de Francis Bacon e René Descartes, colocando o ser humano acima da natureza, como o condutor central do planeta, na qual suas necessidades estão acima de tudo.

Segundo Fischer et al. (2018), na modernidade o domínio e a exploração da natureza passaram a constituir-se baseado na ideia de Bacon conhecida como Imperium Hominis, na qual a natureza e tudo o que nela existe, é concebida como indiferente e o ser humano tem total capacidade de seu uso e controle, passando a acentuar os problemas ambientais.

É esse o tipo de pensamento atual, o racionalismo moderno/científico, no qual o ser humano controla a natureza a seu bel-prazer, sem levar em conta as complicações e consequências disso. Porém, neste mesmo tipo de pensamento, há diversas matrizes distintas, que buscam a harmonia entre desenvolvimento, seres humanos e natureza. Há diferentes pensadores e cientistas que trabalham em prol desse aspecto. Ainda assim, mesmo sabendo dessas diferentes visões, o pensamento cartesiano em nossa sociedade atual (capitalista de hiperprodução e consumo de massa) é o que rege as grandes discussões e tomada de decisões.

Uma nova maneira de pensar o atual modelo de vida, seria buscar uma retomada das ideias dos pré-socráticos, trazer a natureza e os seres ao mesmo patamar, integrando as diversas relações e conexões possíveis. Esse pensamento permite expandir as relações entre todos os seres e a natureza, não apenas quantificá-las como meros objetos que visam a produção e o lucro. Retomar essas ideias é propor profundas reflexões acerca do passado, do presente e o que esperar do futuro, construindo um local mais adequado e respeitoso, indicando, assim, novas direções para se refazer a trajetória da humanidade rumo à resiliência e sustentabilidade planetária.

Desse modo, os autores enxergam como algo positivo essas discussões, recuperando as ideias e reflexões de diferentes pensadores acerca do ambiente e da natureza, trazendo essas reflexões para os dias atuais e buscar contrapontos ao modelo atual de desenvolvimento e pensamento científico. Dessa forma, busca-se valorizar novas ideias, modelos e direções que consideram os distintos pensadores, suas reflexões e o contexto histórico de cada um.

\section{Agradecimentos}

A Coordenação de Aperfeiçoamento de Pessoal de Nível Superior (CAPES) pelo apoio concedido ao financiamento da pesquisa que deu origem a 
esse artigo científico, à Universidade Federal de São Carlos, por tornar possível o doutoramento do primeiro autor.

\section{Referências}

ACOSTA, A. O bem viver: uma oportunidade para imaginar outros mundos. São Paulo: Autonomia Literária, Elefante, 2016. 264p.

ALMEIDA, J. P. A extinção do arco-íris: ecologia e história. Campinas: Papirus, 1988. 62p.

CARSON, R. Primavera silenciosa. São Paulo: Edições Melhoramentos, 1969. 305p.

CARVALHO, I. C. M.; GRÜN, M.; TRAJBER, R. Pensar o ambiente: bases filosóficas para a Educação Ambiental. Brasília: Ministério da Educação, Secretaria de Educação Continuada, Alfabetização e Diversidade, UNESCO, 2006.

CHAUÍ, M. Introdução à história da filosofia: dos pré-socráticos a Aristóteles. São Paulo: Companhia das Letras, 2002. 539p.

DE PAULA, E.M.S.; SILVA, E.V.; GORAYEB, A. Percepção Ambiental e dinâmica geoecológica: premissas para o planejamento e gestão ambiental. Revista Sociedade \& Natureza, Uberlândia, v. 26, n. 3, p. 511 - 518, 2014.

FELIPPE, M.L. Casa: uma poética da terceira pele. Psicologia \& Sociedade, Belo Horizonte, v. 22, n. 2, p. 299 - 308, 2010.

FIGUEIREDO, R. A. de; SILVA, P. R. da. Aconselhamento filosófico aplicado à Educação Ambiental e agroecologia. Revista Educação, Cultura e Sociedade, Sinop, v. 8, n. 2, p. 429 - 440, 2018.

FISCHER, M. L. et al. Comunicações sobre a crise hídrica: a internet como ferramenta de sensibilização ética. Sustentabilidade em Debate, Brasília, v. 9, n. 1 , p. $158-171,2018$.

GRÜN, M. Descartes, Historicidade e Educação Ambiental. In: CARVALHO, I.C. M.; GRÜN, M.; TRAJBER, R. (Orgs). Pensar o Ambiente: bases filosóficas para a Educação Ambiental. Brasília: Ministério da Educação, UNESCO, p. 63 - 78, 2006.

HERCULANO, S.C. Do desenvolvimento (in)suportável à sociedade feliz. In: GOLDENBERG, M. (Org). Ecologia, ciência e política. Rio de Janeiro: Revan, p. $9-48,1992$.

JACOBI, P.R. Educação Ambiental, cidadania e sustentabilidade. Cadernos de Pesquisa, São Paulo, n. 118, p. 189 - 205, 2003.

JORDÃO, F.V. Natureza, sentido e liberdade em Kant. Revista Filosófica de Coimbra, Coimbra, v. 1, p. $63-81,1992$. 
LAYRARGUES, P.P. Muito além da natureza: Educação Ambiental e reprodução social. In: LOUREIRO, C.F.B.; LAYRARGUES, P.P.; CASTRO, R. S. de. (Orgs). Pensamento complexo, dialética e Educação Ambiental. São Paulo: Cortez, p. 72 - 103, 2006.

LENOBLE, R. História da ideia de natureza. Rio de Janeiro: Edições 70 Melhoramentos, 2002. 367p.

MARICONDA, P.R. O controle da natureza e as origens da dicotomia entre fato e valor. Scientlae Studia, São Paulo, v. 4, n. 3, p. 453 - 472, 2006.

PELIZZOLI, M.L. A emergência do paradigma ecológico: reflexões éticofilosóficas para o século XXI. Petrópolis: Vozes, 1999. 61p.

ROHDEN, N. Kant: o ser humano entre natureza e liberdade. In: CARVALHO, I.C. M.; GRÜN, M.; TRAJBER, R. (Orgs). Pensar o Ambiente: bases filosóficas para a Educação Ambiental. Brasília: Ministério da Educação, UNESCO, p. 111 - 124, 2006.

SAUVÉ, L. Educação Ambiental: possibilidades e limitações. Educação e Pesquisa, São Paulo, v. 31, n. 2, p. 317-322, 2005.

SAWAIA, B. B. Espinosa: o precursor da ética da Educação Ambiental com base nas paixões humanas. In: CARVALHO, I.C. M.; GRÜN, M.; TRAJBER, R. (Orgs). Pensar o Ambiente: bases filosóficas para a Educação Ambiental. Brasília: Ministério da Educação, UNESCO, p. 79 - 92, 2006.

SEVERINO, A. J. Bacon: a ciência como conhecimento e domínio da natureza. In: CARVALHO, I.C. M.; GRÜN, M.; TRAJBER, R. (Orgs). Pensar o Ambiente: bases filosóficas para a Educação Ambiental. Brasília: Ministério da Educação, UNESCO, p. 51 - 62, 2006.

SOFFIATI, A. A natureza no pensamento liberal clássico. Revista de Direito Ambiental, São Paulo, v. 5, n. 20, p. 159 - 176, 2000.

THOMAS, K. O homem e o mundo natural: mudanças de atitude em relação as plantas e aos animais (1500-1800). São Paulo: Companhia das Letras, 1996. 454p.

UNGER, N. M. Os pré-socráticos: os pensadores originários e o brilho do ser. In: CARVALHO, I.C. M.; GRÜN, M.; TRAJBER, R. (Orgs). Pensar o Ambiente: bases filosóficas para a Educação Ambiental. Brasília: Ministério da Educação, UNESCO, p. 25 - 32, 2006. 